\title{
Design a Marble Rollercoaster
}

\author{
Michelle DeAlmeida ${ }^{1}$ \\ ${ }^{1}$ Affiliation not available
}

June 7, 2021

Suggested Time: 50 minutes

\section{Overview}

Students will learn about the science and math of rollercoasters and then apply what they learned to construct a marble rollercoaster with a loop. Students will then use Flipgrid to demonstrate their rollercoaster and explain the physics, math, and engineering design process they used.

\section{Vocabulary}

- Potential energy

- Kinetic energy

- Gravity

- Acceleration

- Deceleration

- Velocity

- Newton's First Law of Motion

- Friction

\section{Objectives}

- Students will learn about the science of rollercoasters including potential and kinetic energy.

- Students will design and construct a rollercoaster for a marble that includes a loop.

- Students will determine the height the marble needs to start at along with the slope of the track to complete the loop.

- Using what they have learned, students will calculate the potential energy of the marble at the start of the rollercoaster. Using this they will calculate the velocity of the marble before it enters the loop.

\section{Next Generation Science Standards}

- PS3.A: Definitions of Energy

- PS3.B: Conservation of Energy and Energy Transfer

\section{Common Core Mathematical Standards}

- CCSS.MATH.CONTENT.7.EE.B.3

- CCSS.MATH.PRACTICE.MP4

- CCSS.MATH.PRACTICE.MP1

Required Project Materials (per group)

- One marble

- One foam pool noodle or pipe insulation, cut in half 
- Duct Tape

\section{Multimedia Resources}

- How Roller Coasters Work. https://science.howstuffworks.com/engineering/structural/ roller-coaster $3 . \mathrm{htm}$

- Rollercoasters. https://www. explainthatstuff.com/rollercoasters.html

\section{Before the Lesson/ Background Information}

- None

\section{The Lesson}

\section{Part 1: Research rollercoasters (10 mins)}

1. Tell students that they will be working in groups of 2-3 to design and build a roller coaster for a marble with a loop. They will need to make sure that the marble completes the loop without falling out.

2. Have students do some research on the science of rollercoasters by reading the two links above.

3. Engage the class in a discussion about potential and kinetic energy. Review the equations for both and their relevance to rollercoasters. Discuss how the starting height and the slope of the rollercoaster will affect whether the marble will stay in the track.

\section{Part 2: Design and construct your rollercoaster (30 mins)}

1. Groups should first make a rough sketch of their design before they start to build the track.

2. Construct the rollercoaster and test to see if it works. Revise design and keep testing until the marble completes the loop.

3. Sketch successful track design and label where the potential energy and kinetic energy are at their maximums. Label the height that the marble starts from as well as the slope of the initial downward track.

4. Calculate the maximum potential energy and use this to calculate the velocity when the marble enters the loop. Start the marble at an even higher height and see what happens to the velocity. Change the slope and see how the velocity is affected.

\section{Part 3: Record Flipgrid (10 mins)}

1.Have each group record a Flipgrid video showing their successful marble run.

2. In the video each group should discuss/show:

a. The engineering design process they followed

b. The calculations showing the velocity as the marble enters the loop

c. The slope calculation (rise divided by run) 